\title{
Acute toxic exposure in children: an overview
}

\author{
Fábio Bucaretchi, ${ }^{1}$ Emílio C. E. Baracat $^{2}$
}

\begin{abstract}
Objective: To review the literature on acute toxic exposure in children, excluding envenomations.

Sources of data: MEDLINE review (emphasis on the past decade), including the American Academy of Clinical Toxicology and the European Association of Poison Centres and Clinical Toxicologists' position statements and position papers (peer-reviewed information based on scientific evidence and broad consensus) on gastrointestinal decontamination, multiple-dose activated charcoal and urine alkalinization.

Summary of the findings: Acute toxic exposure in children is a common event, mainly in children under six years of age. Death is rare. Although widely employed, there is no evidence that gastrointestinal decontamination and multiple-dose activated charcoal improve the outcome of poisoned patients. Very few efficient antidotes are used on a consistent basis, and some of them are very expensive and not available in Brazil.

Conclusions: Ipecac syrup and cathartics should not be administered on a routine basis in acute toxic exposures in outpatient treatment. Excluding the contraindications, single-dose activated charcoal and gastric lavage may be considered within one hour of ingestion if a patient ingested a potentially toxic amount or a potentially lethal amount, respectively. Whole bowel irrigation, multiple-dose activated charcoal and urine alkalinization may be considered in a few situations. Fomepizole and octreotide are safe and efficient antidotes, which can be used in the treatment of alcohol (methanol and ethylene glycol) and sulfonylureas poisoning, respectively.
\end{abstract}

J Pediatr (Rio J). 2005;81(5 Suppl):S212-S222: Poisoning, gastrointestinal decontamination, charcoal, antidotes, children.

\section{Introduction}

Exposure to toxic substances (pharmaceutical or not) is a common event in pediatrics. ${ }^{1-10}$ According to the 2003 American Association of Poison Control Centers' Toxic Exposures Surveillance System data, which provide a wide coverage of the U.S. territory, there are approximately 2.4 million exposures, and 93 and $52 \%$ of them occurs in the household and in children younger than six years, respectively. ${ }^{1}$ Most exposures in this age group are unintentional $(99.4 \%)$, with less morbidity and mortality if

1. PhD. Assistant professor, Department of Pediatrics, Medicine School, Universidade Estadual de Campinas (UNICAMP), Campinas, SP, Brazil. Centro de Controle de Intoxicações, UNICAMP.

2. PhD. Assistant professor, Department of Pediatrics, Medicine School, Universidade Estadual de Campinas (UNICAMP), Campinas, SP, Brazil.

Suggested citation: Bucaretchi F, Baracat EC. Acute toxic exposure in children: an overview. J Pediatr (Rio J). 2005;81(5 Suppl):S212-S222. compared to other pediatric age groups; however, among adolescents, $45.9 \%$ of the exposures were intentional. ${ }^{1}$

In the 1940s, approximately 500 children died in the USA every year, due to toxic exposures. Current data show important prophylactic (active and passive) measures established in order to reverse this situation, including mainly the mandatory use of child-resistant packaging, permanent public education and the creation of poison control centers. ${ }^{1-4,9,11-12}$ Poison control centers are a very good example of this, with an excellent cost-benefit ratio, significantly reducing the number of unnecessary referrals to emergency rooms and the number of invasive procedures, by providing, in most cases, specialized guidance and telephone follow-up with remarkable success. ${ }^{1-4,9,11-12}$ Moreover, poison control centers act as "surveillance tools," and the analysis of the information, collected in a uniform and systematic manner, has helped to devise adequate public policies for toxic exposure surveillance. ${ }^{1}$ 
In Brazil, 25 of 33 regional centers, each with its own characteristics, fed the Brazilian National System of Toxic and Pharmacological Information (SINITOX) in 2002, according to which there were 75,212 exposures $(25.4 \%$ in children younger than five years) and 375 deaths (31 in children younger than five years). ${ }^{10}$ The major agents, classified according to age group, are listed in Table 1, including mainly medicines, household products, and venomous animals. In terms of lethality, pesticides (organophosphorates), medicines and rat poisons whose use is not authorized (aldicarb) are the major agents that victimize children (Table 2 ). Accidents involving venomous animals are also of great importance, but they are not within the scope of the present study. By analyzing Brazilian data, we may speculate that there is a large number of understatements, and that nearly $1 \%$ of the population has some kind of exposure every year. ${ }^{1}$ Most cases treated by poison control centers are referred from health centers; in other words, poison control centers are not as much sought after by laypersons in Brazil as they are in industrialized countries. ${ }^{1}$ An important measure has been recently taken by the Brazilian National Health Surveillance Agency (ANVISA, 2005): the creation of the National Network of Information and Poison Control Centers (CIATs), which is in charge of approving the guidelines for the qualification of the centers in operation. Among the first measures is the availability of a hotline (0800) for all CIATs in the Brazilian territory, with an automatic regional search.

\section{General approach}

Whenever possible, the following should be determined: the product involved (pharmaceutical, non-pharmaceutical, or illicit drug); route of exposure (in most cases, a single product is ingested); the estimated dose (toxic or nontoxic); whether the exposure was unintentional or intentional (more serious), where it took place [at home, at the neighbor's house, in a vacant lot, at parties (raves) ...] and who was in charge of the child (assess the possibility of maltreatment or Munchausen's syndrome by proxy); how long ago exposure occurred (less or more than one hour ago); what measures were taken (induced vomiting; gastric lavage, often unnecessary, is performed and then the poison control center is contacted either during or after the procedure); patient health status (with or without clinical signs and symptoms); whether referral to an emergency room is necessary; whether the use of gastrointestinal decontamination is indicated in order to expedite poison elimination and whether the use of antidotes is recommended; whether it is necessary to carry out toxicological screening or specific blood tests which may help to establish the diagnosis and treatment. ${ }^{4,9}$

Qualitative toxicological lab tests are restricted to the clinical management of patients, but they should be considered for a possible identification of illicit substances, thus helping with the diagnosis of maltreatment and child abuse. 4,9 Quantitative tests for certain toxic agents, correlated with time of ingestion, may be a useful tool in

Table 1 - Frequency of major agents according to age range in toxic exposures reported to SINITOX in 2002

\begin{tabular}{|c|c|c|c|c|c|c|}
\hline Agents & $\begin{array}{c}<5 \text { years old } \\
n\end{array}$ & $\begin{array}{c}\text { 5-9 years old } \\
n\end{array}$ & $\begin{array}{c}\text { 10-19 years old } \\
n\end{array}$ & $\begin{array}{c}>20 \text { years old } \\
n\end{array}$ & $\begin{array}{c}\text { Total } \\
\mathbf{N}\end{array}$ & $\%$ \\
\hline Medicines & 7,138 & 1,600 & 3,124 & 8,378 & 20,240 & 26.9 \\
\hline Venomous animals & 1,277 & 1,463 & 3,072 & 12,165 & 17,977 & 23.9 \\
\hline Sanitary products & 3,583 & 400 & 221 & 2,342 & 6,546 & 8.7 \\
\hline Agrochemicals & 586 & 138 & 712 & 4,155 & 5,591 & 7.4 \\
\hline Industrial chemical products & 1,603 & 235 & 479 & 2,336 & 4,653 & 6.2 \\
\hline Non-venomous animals & 502 & 387 & 683 & 2,782 & 4,354 & 5.8 \\
\hline Rat poison & 1,214 & 140 & 915 & 2,050 & 4,319 & 5.7 \\
\hline Pesticides & 717 & 111 & 303 & 1,116 & 2,247 & 3.0 \\
\hline Abuse drugs & 54 & 21 & 578 & 1402 & 2,055 & 2.7 \\
\hline Plants & 798 & 325 & 191 & 414 & 1728 & 2.3 \\
\hline Veterinary products & 201 & 27 & 94 & 643 & 965 & 1.3 \\
\hline Metals & 140 & 33 & 41 & 624 & 838 & 1.1 \\
\hline Cosmetics & 482 & 43 & 51 & 100 & 676 & 0.9 \\
\hline Food & 79 & 51 & 88 & 254 & 472 & 0.6 \\
\hline Others and unidentified & 716 & 306 & 384 & 1,145 & 2,551 & 3.4 \\
\hline Total & 19,090 & 5,280 & 10,936 & 39,906 & 75,212 & 100,0 \\
\hline$\%$ & 25.4 & 7.0 & 14.5 & 53.1 & 100.0 & \\
\hline
\end{tabular}

SINITOX = Sistema Nacional de Informações Tóxico-Farmacológicas (National System of Toxic and Pharmacological Information). 
Table 2 - Frequency of deaths according to agents and age range in toxic exposures reported to SINITOX in 2002

\begin{tabular}{|c|c|c|c|c|c|c|}
\hline Agents & $\begin{array}{c}<5 \text { years old } \\
n\end{array}$ & $\begin{array}{c}\text { 5-9 years old } \\
n\end{array}$ & $\begin{array}{c}\text { 10-19 years old } \\
n\end{array}$ & $\begin{array}{c}>20 \text { years old } \\
n\end{array}$ & $\begin{array}{c}\text { Total } \\
\mathbf{N}\end{array}$ & $\%$ \\
\hline Agrochemicals & 4 & 0 & 15 & 112 & 131 & 34.9 \\
\hline Medicines & 6 & 0 & 11 & 44 & 61 & 16.3 \\
\hline Rat poison & 3 & 2 & 10 & 44 & 59 & 15.7 \\
\hline Venomous animals & 8 & 9 & 2 & 26 & 45 & 12.0 \\
\hline Others and unidentified & 4 & 0 & 1 & 13 & 18 & 4.8 \\
\hline Industrial chemical products & 2 & 0 & 2 & 12 & 16 & 4.3 \\
\hline Abuse drugs & 0 & 0 & 3 & 8 & 11 & 2.9 \\
\hline Sanitary products & 2 & 0 & 0 & 8 & 10 & 2.7 \\
\hline Pesticides & 0 & 0 & 1 & 9 & 10 & 2.7 \\
\hline Veterinary products & 0 & 0 & 0 & 8 & 8 & 2.1 \\
\hline Food & 1 & 2 & 0 & 1 & 4 & 1.1 \\
\hline Non-venomous animals & 0 & 0 & 0 & 1 & 1 & 0.3 \\
\hline Metals & 1 & 0 & 0 & 0 & 1 & 0.3 \\
\hline Plants & 0 & 0 & 0 & 0 & 0 & 0.0 \\
\hline Cosmetics & 0 & 0 & 0 & 0 & 0 & 0.0 \\
\hline Total & 31 & 13 & 45 & 286 & 375 & \\
\hline$\%$ & 8.3 & 3.5 & 12.0 & 76.3 & 100.0 & \\
\hline Total of cases by age range & 19,090 & 5,280 & 10,936 & 39,906 & 75,212 & \\
\hline Lethality by age range (\%) & $(0.16)$ & $(0.24)$ & $(0.41)$ & $(0.72)$ & $(0.50)$ & \\
\hline
\end{tabular}

SINITOX = Sistema Nacional de Informações Tóxico-Farmacológicas (National System of Toxic and Pharmacological Information).

assessing risk and implementing treatment, such as in toxic exposure to acetaminophen, iron salts, salicylates, theophylline, phenytoin and carbamazepine. Other tests include the assessment of enzyme activity (e.g.: acetylcholinesterase in exposure to organophosphorates and carbamates), methemoglobinemia (e.g.: exposure to direct oxidant drugs such as dapsone) and carboxyhemoglobin (exposure to carbon monoxide). ${ }^{4,9}$

In several situations, the toxic substance is not identified on admission, especially when caretakers carry out several household chores and the child spends most of the day without being watched by an adult. To facilitate the identification of the substance, it is crucial to perform a thorough physical examination, assessing mainly vital signs, temperature, hydration of mucous membranes, pupil response measurements, neurological examination, reflexes, in order to identify a toxic syndrome (Table 3). In several cases, the clinical picture is "mixed." Thus, for instance, a patient exposed to tricyclic antidepressants may have some anticholinergic symptoms, central nervous system depression, and seizures. ${ }^{4,9}$

In severe cases, which are rare, stabilization of cardiorespiratory function is of paramount importance, following the guidelines for advanced life support. At the emergency room, examination should prioritize the airways $(A)$, then breathing (B), circulation (C), neurological functions and exposure (including control over hypothermia and hyperthermia). Children are at great risk for dehydration, and blood volume replacement should be readily implemented if the quality of distal pulses is impaired or if capillary refill time is increased. The restricted glycogen stores in infants and preschoolers increase the risks of hypoglycemia after toxic exposure. This fact is especially important in case of ethanol intoxication; therefore, glucose at $10-25 \%$, in the dose of $250 \mathrm{mg} / \mathrm{kg}$, should be infused immediately. Patients with low level of alertness and respiratory depression on admission should receive $2 \mathrm{mg}$ of IV naloxone. Higher doses of this antidote may be necessary if opioid poisoning is confirmed. Other measures include the management of seizures, correction of electrolytic disorders and metabolic acidosis. ${ }^{49}$ One should recall that every patient with intentional toxic exposure must be referred to a psychiatrist as soon as his/her health status allows.

\section{Gastrointestinal decontamination}

Attempts to reduce exposure to toxic agents through measures that promote gastric emptying or decrease intestinal uptake have been made for many years. However, there are several restrictions concerning the actual efficacy of these procedures during prehospital or hospital care. ${ }^{12-}$ ${ }^{26}$ Also, severe poisonings and mortality are low, especially in children younger than six years; most of the time, these procedures are not necessary and are used in an iatrogenic fashion. ${ }^{12-26}$ In a joint partnership, the American Academy of Clinical Toxicology (AACT) and the European Association of Poisons Centres and Clinical Toxicologists (EAPCCT) have 
reported on these procedures since 1997, based on the best available evidence, and have proposed treatment guidelines with strong restrictions upon the generalized indication of gastrointestinal decontamination measures. ${ }^{13-21}$ In general, such propositions have been supported by other large associations, including the American Academy of Pediatrics (AAP). ${ }^{12}$

\section{Syrup of ipecac}

Ipecac contains two pharmacologically active ingredients (emetine and cephalin), provoking emesis by peripheral (gastric mucosal receptors and central stimulation. ${ }^{13,18,22-}$ ${ }^{24}$ Although it is efficient in inducing vomiting, with $80-85 \%$ of patients vomiting for 15-30 minutes after a single dose, the amount of marker removed is completely variable and decreases with time (experimental and volunteer studies), and there is no evidence that poisoned patients show improvement after taking it; therefore, it should not be used on a routine basis in emergency rooms. ${ }^{3,13,18,22-26}$ There is a paucity of data in favor of its early administration after ingestion of potentially toxic substances; in fact, this syrup may delay the administration or reduce the efficacy of activated charcoal, of oral antidotes such as $\mathrm{N}$-acetylcysteine or of bowel irrigation. ${ }^{13,18}$, It is totally contraindicated in patients with low level of alertness or who ingested caustic substances or hydrocarbons, due to the higher risk of injury to the gastric mucosa and aspiration, respectively. ${ }^{13,18}$

In the early 1980s, the AAP recommended the storage of syrup of ipecac at home, as well as its use for induced vomiting only after a medical appointment or after contacting a poison control center, although no large study that confirmed the efficacy, safety and validity of ipecac for the prevention of poisonings had been carried out. ${ }^{12}$ AAPCC data, between 1983 and 2003, reveal a progressive and constant decrease in the indication of syrup of ipecac. ${ }^{1-2}$ The biggest change in this profile is due to the epidemiological diagnosis that most exposures do not pose any risks or have a low risk of toxicity. ${ }^{1}$ AACT and EAPCCT no longer recommend the use of the syrup of ipecac in the emergency room and, quite recently, ${ }^{13,18}$ AAP (2003) reassessed its position and contraindicated the use of the syrup of ipecac at home. ${ }^{12}$

An AAPCC consensus panel (2005), considering an acceptable risk-benefit ratio, proposed a new treatment guide, in which it restricted the use of syrup of ipecac in prehospital care, always after consulting with the poison control center, emergency room or qualified medical staff, in the following cases: when there is no formal contraindication for the use of the syrup of ipecac; when there is no large risk of toxicity; there is no effective alternative therapy to decrease intestinal uptake (e.g.: activated charcoal); time for patient admission to the emergency room exceeds one hour and if the patient receives the syrup of ipecac within 30-90 minutes after ingestion; when the syrup of ipecac does not interfere negatively on the hospital treatment to be implemented. 24 The syrup of ipecac is seldom indicated in Brazil, since it is not commercially available and is only prepared at compounding pharmacies.

\section{Gastric lavage}

Gastric lavage has been widely used for over 180 years in gastrointestinal decontamination procedures. $3,14,20,23$ Nevertheless, the efficacy of this procedure remains unclear. ${ }^{3,14,20,23}$ Gastric lavage consists of the insertion of an adequate-sized orogastric tube with administration and sequential aspiration of a small amount of fluids for the removal of toxic substances from the stomach, including large amounts of wholly or partially digested tablets and toxic plant remains. $3,14,20,23$

Similarly to the syrup of ipecac, the amount of marker removed varies a lot and decreases with time, with no evidence described in volunteer studies and clinical trials that gastric lavage improves the status of patients; quite on the contrary, it may cause severe morbidity. ${ }^{3,14,20,23}$ Gastric lavage should only be considered when a patient has ingested a potentially lethal dose and if the procedure is performed within 60 minutes of ingestion. $3,14,20,23$ It is estimated, however, that more severe cases, involving suicidal attempts, in which this procedure would supposedly be more indicated, do not get to the hospital before 2-3 hours of exposure. ${ }^{23}$ The procedure should only be performed if airways are intact; in case of central nervous system or respiratory depression, the airways must be protected before the procedure. It is also contraindicated in patients who ingested caustic substances or hydrocarbons. The most common complications are aspiration pneumonia; laryngospasm; traumatic injuries to the oropharynx, esophagus and/or stomach; water imbalance (water intoxication and hyponatremia) and electrolytic disorder (hypernatremia, when large amounts of saline solution are used); conjunctival hemorrhage; one should recall that combative patients have a higher risk for complications. ${ }^{3,14,20,23}$

Recommended doses correspond to $10 \mathrm{ml} / \mathrm{kg}$ of saline solution at $0.9 \%$, heated at $38^{\circ} \mathrm{C}$, to prevent hypothermia; in adolescents, $200-300 \mathrm{ml}$ may be used per infusion of saline solution at $0.9 \%$ or of water. The volume of lavage fluid returned should be the same as the infusion volume. 14,20 Although there is no evidence, ${ }^{27}$ gastric lavage may accelerate gastric emptying into the small intestine, especially when large infusion volumes are administered, increasing the risk of intestinal uptake. ${ }^{14,20}$ Lavage should be continued until the recovered lavage is clear. ${ }^{14,20}$

\section{Single-dose activated charcoal}

Activated charcoal has been used to treat toxic exposure due to ingestion for over 100 years, and is still largely used $^{1-3,15,21,23,28}$ (Table 4).

Activate charcoal for human use is a highly porous form of charcoal, with a surface area of $950-2,000 \mathrm{~m}^{2} / \mathrm{g}$, which is able to adsorb a large amount of toxic substances and has high affinity for compounds with molecular weight between 10 and 100 Da. 1-3,15,21,23 In Brazil, only the powder formulation is available. Some forms consist of aqueous formulations that contain preservatives, sorbitol, sodium bicarbonate or povidone, which may cause 
complications or interfere with its efficacy. Tablets or capsules, on the other hand, have a poorer efficacy than powdered charcoal dissolved in water. ${ }^{15,21}$

Based on studies with human volunteers, the efficacy of activated charcoal also decreases with time; it is more efficacious if administered within one hour of ingestion. 15,21,23 Even though there are empirical recommendations for the use of activated charcoal several hours after the ingestion of anticholinergic substances, which may delay gastric emptying, additional controlled studies should be conducted to validate this procedure. ${ }^{29}$ Single-dose activated charcoal administration can be considered in case of ingestion of potentially toxic doses and of substances that are provably adsorbed by activated charcoal, but there is no evidence that it may improve the prognosis of affected patients. ${ }^{15,21,23}$ However, Seger advocates that the criteria for the recommendation of single-dose activated charcoal should be more strict, and suggests that it should be administered only in severe cases of poisoning, since the risk-benefit ratio is not wellestablished yet. ${ }^{28}$ The use of single-dose activated charcoal should only occur if the airways are intact; in case of central nervous system or respiratory depression, the airways must be protected before the administration of activated charcoal. 15,21,23,28 Activated charcoal is inefficient in exposures to alcohols, iron salts and lithium; and contraindicated in exposures to hydrocarbons, essential oils, sodium hypochloride and caustic substances. ${ }^{15,21}$

The conventionally recommended doses, according to age, are: $<1$ year, $1 \mathrm{~g} / \mathrm{kg}$; 1 - 12 years, $25-50 \mathrm{~g}$; adolescents and adults, $25-100 \mathrm{~g}$, and the combination with laxatives is not recommended. ${ }^{15,21}$ As charcoal is in powder form, it must be diluted in water solution in the concentration of 10 $20 \%$. In children, oral administration is not always efficient, once it may not be well accepted; therefore, it should be infused through a nasogastric tube. 15,21,23,28,30-32 Complications include vomiting, caused directly by activated charcoal, or associated with the previous use of the syrup of ipecac or sorbitol. ${ }^{15,21,23,28,30-32}$ There have been reports of aspiration pneumonia, as well as of tracheal obstruction, severe lung injury and pleural effusion due to direct administration of activated charcoal in the respiratory tree. ${ }^{28}$ Gastric perforation by the tube has also been reported, with instillation of activated charcoal in the peritoneum, developing into purulent peritonitis. ${ }^{28}$ There have not been reports of obstipation or intestinal obstruction caused by single-dose activated charcoal. 15,21 There may be transient corneal abrasion by direct contact. $15,21,28$

Although it may be interesting to store activated charcoal at home to be administered in an emergency situation, instead of the syrup of ipecac, there is scant evidence regarding safety and the actual benefit of this procedure in pediatrics. $12,15,21,23,28,31-32$ Moreover, there is a remarkable possibility of failure in the administration, due to poor acceptance of the therapeutic dose, even when it is given together with a soft drink. ${ }^{31-32}$

\section{Cathartics}

Salines (magnesium citrate or sulfate) are the major cathartics used in poisoned patients, in addition to those containing sorbitol. ${ }^{3,16,23,33}$ In other formulations available overseas, sorbitol is added to activated charcoal, thus improving its palatability. ${ }^{16,33}$ Arguably, the use of these substances causes an increase in intraluminal contents due to osmotic fluid retention, with consequent acceleration of intestinal transit, reducing the time of exposure to the toxic agent or to the toxic agent-activated charcoal complex. ${ }^{16,33}$ However, no consistent studies exist that support its administration in one single dose or in multiple doses, and there is no evidence that cathartics, combined or not with activated charcoal, reduce the bioavailability of toxic agents or improve the prognosis of affected patients; in addition, its use is not supported by AACT and by EAPCCT. ${ }^{16}$

If one decides for the administration of cathartics, and occasionally for the administration of serial doses of activated charcoal, only a single dose should be given, in order to minimize the adverse effects of cathartics. The following single doses have been used in children: $250 \mathrm{mg} / \mathrm{kg}$ of magnesium sulfate (maximum of $30 \mathrm{~g}$ ) $; 4.3 \mathrm{ml} / \mathrm{kg}$ of sorbitol at $35 \%$ (or $0.5-2 \mathrm{~g} / \mathrm{kg}$, maximum of $50 \mathrm{~g}$ ); $4 \mathrm{ml} / \mathrm{kg}$ of magnesium citrate at $10 \%$ (maximum of $250 \mathrm{ml}$ ); with careful administration to infants (younger than one year). ${ }^{16,33}$ In a controlled study with a series of children younger than five years, sorbitol was more efficient than cathartics compared to magnesium citrate and magnesium sulfate, all combined with single-dose activated charcoal. ${ }^{33}$ Its use is contraindicated in patients with paralytic ileum; intestinal semi-occlusion or obstruction; hypovolemia or electrolytic disorders; with renal failure (cathartics containing magnesium); or after ingestion of caustic substances. $3,16,23$ Complications caused by single doses of cathartics included nausea, colics, vomiting and transient hypotension; and those caused by multiple or excessive doses were dehydration, hypernatremia (cathartics containing $\mathrm{Na}^{++}$) and hypermagnesemia (cathartics containing $\mathrm{Mg}^{++}$). 16,23,33

\section{Bowel irrigation}

Bowel irrigation consists of an attempt to reduce exposure and uptake of certain toxic agents by enteral administration, through a nasogastric tube, of large volume and in a short time period, of an osmotically balanced solution of polyethylene glycol. $3,17,19,23$ The polyethylene glycol solution is not absorbed and has been widely used in other situations (e.g.: "preparation" of colon for surgery or colonoscopy), both in children and in adults, and its use is safe. 17,19,23

Although some studies with volunteers show a remarkable reduction in the bioavailability of some drugs, no clinical trials or conclusive evidence exist that bowel irrigation improves the prognosis of affected patients. ${ }^{17,19,23}$ However, such procedure should be considered in cases of ingestion of potentially toxic doses of: sustained-release or enteric coated drugs (mainly if admitted after two hours of ingestion); iron salts; body packers. ${ }^{17,19,23}$ Bowel irrigation is contraindicated in patients with intestinal obstruction and/or perforation, paralytic ileum, gastrointestinal hemorrhage, 
uncontrollable vomiting or hemodynamic instability. ${ }^{17,19}$ It should only be used if the airways are intact; in case of central nervous system or respiratory depression, the airways must be protected before the procedure. The simultaneous administration of bowel irrigation and activated charcoal may interfere with the adsorption of the latter. ${ }^{17,19}$

Since large amounts of polyethylene glycol solution are necessary, it should be administered via a nasogastric tube. ${ }^{17,19}$ Infusion should be maintained until a clear effluent is eliminated by the rectum, which may take hours. ${ }^{17,19}$ Nevertheless, this does not rule out the possibility that the whole intestine has been "cleared", unless the toxic substance is radiopaque and can be quantified. ${ }^{23}$ Although no dose-response assessments are available, the recommended doses, according to age, are: nine months to six years, $500 \mathrm{ml} /$ hour; 6-12 years, 1,000 ml/hour; adolescents and adults, 1,500-2,000 ml/hour.17,19 Complications include nausea, colics and vomiting, in addition to the risk of pulmonary aspiration in patients without airway protection. 17,19

Table 3 - Major toxic syndromes, clinical manifestations and agents involved

\begin{tabular}{ll}
\hline Syndromes & $\begin{array}{l}\text { Clinical manifestations / } \\
\text { Lab test alteration }\end{array}$ \\
\hline Neurological depression & Ranging from sleepiness to coma \\
& \\
Anticholinergic & $\begin{array}{l}\text { Restleness and/or sleepiness, } \\
\text { visual hallucinations, dry mucosal membranes, } \\
\text { skin flushing, mydriasis, urinary retention, } \\
\text { hyperthermia }\end{array}$ \\
$\begin{array}{l}\text { Release in the } \\
\text { extrapyramidal system } \\
\text { (acute dystonia) }\end{array}$ & $\begin{array}{l}\text { Hypertonia, muscular spasms, } \\
\text { cogwheel rigidity, catatonia, akathisia, } \\
\text { eye-rolling movements, opisthotonos, } \\
\text { poor facial mimic, monotonous cry }\end{array}$
\end{tabular}

Agents

Benzodiazepines, carbamazepine, phenobarbital, opioids, imidazoline derivatives (topical decongestants), clonidine, $\mathrm{H} 1$ histamine antagonists, tricyclic antidepressants, acetylcholinesterase inhibitors (specially organophosphorate), salicylates, alcohols (ethanol, methanol, ethylene glycol or isopropanol), carbon monoxide

H1 histamine antagonists, atropine, scopolamine (hyoscine), phenothiazines, tricyclic antidepressants, vegetals from the belladonne family (for example, "Angel's trumpet")

Dopamine D2 blockers (domperidone), metoclopramide, butyrophenones (haloperidol), phenothiazines

Hydantoin, piperazine, carbamazepine, $\mathrm{H} 1$ histamine antagonists, carbon monoxide, alcohols, benzodiazepines

Convulsive
Increased sympathetic activity

Increased

parasympathetic

activity

Rhabdomyolysis

Shock

Hyperemesis

Methemoglobinemia
Tachycardia, hypertension, skin flushing, hyperthermia

Bradycardia, sudoresis, muscular weakness, muscular fasciculation, sialorrhea, broncorrhea, wheezes, myosis, diarrhea, decrease in the acetylcholinesterase activity

Generalized myalgia, dark urine (myoglobinuria), acute renal failure, increase in levels of total serum creatine kinase
Teophiline, cocaine, amphetamines, ecstasy, caffeine, carbamazepine, isoniazid, tricyclic antidepressants, carbon monoxide, salicylate, organochlorines

Theophylline, cocaine, amphetamines, ecstasy, systemic decongestants

Acetylcholinesterase inhibitors (organophosphorus pesticides and carbamates, prostigmin)

Cocaine, amphetamines, ecstasy (malignant hyperthermia)

Arsenic, iron salts

Aspirin, theophylline, caustics, iron salts

Cyanosis, tachycardia, asthenia, irritability, breathing effort, neurological depression, convulsions
Sulphones, aniline and derivatives, sulphonamides, nitrates and nitritis, chlorates, quinones, metoclopramide, phenazopyridine, local anesthetics, methylene blue 


\section{Increased clearance}

\section{Multiple-dose activated charcoal}

The administration of multiple doses of activated charcoal presupposes that the administration of repeated doses of activated charcoal may increase gastrointestinal elimination of drugs that are present at toxic levels in the systemic circulation and that have a long half-life, low volume of distribution, enterogastric, enteroenteric or enterohepatic circulation. 23,34 However, there are no controlled clinical trials with poisoned patients showing a reduction in morbidity and mortality after the use of this procedure, including the definition of better doses and better dosing intervals. ${ }^{23,34}$

Based on experimental clinical trials, multiple-dose activated charcoal should be considered in case of ingestion of high doses of dapsone, carbamazepine, phenobarbital, theophylline or quinine, which may imply risk of life. 23,34 Studies with volunteers suggest that multiple-dose activated charcoal can increase the clearance of amitriptyline, dextropropoxyphene, phenytoin, digoxin, digitoxin, piroxicam, nadolol, sotalol and phenylbutazone. ${ }^{34}$ The use of this procedure to treat exposure to salicylates is controversial; therefore, its recommendation is arguable. ${ }^{34}$ The recommended doses (0.25-1 g/kg/dose; 25-50 g for adolescents and adults) and the dosing intervals (usually every 2-4 hours) vary considerably, and infusion via a nasogastric tube is often necessary. ${ }^{34}$ Its use is contraindicated in patients with paralytic ileum, intestinal semi-occlusion or obstruction, or with central nervous system depression without airway protection. ${ }^{34}$ The major complications, which often occur in patients with no indication for this procedure, include pulmonary aspiration (even with the first doses), hypernatremia or hypermagnesemia (inadequate use of repeated doses of cathartics), corneal abrasion, intestinal obstruction, and acute appendicitis. ${ }^{23,34-37}$

\section{Alkaline diuresis}

Urine alkalinization consists of an attempt to increase the clearance of certain toxic agents by intravenous administration of sodium bicarbonate with the aim of obtaining a urine $\mathrm{pH} \geq 7.5$ (7.5-8.5).4,23,38 Given the fact that cell membranes are more permeable to fat-soluble and nonionized substances, the reabsorption rate of a drug from the renal tubular lumen to the bloodstream increases if the drug in nonionized, decreasing otherwise. 4,23,38 Since the ionization of a weak acid increases in alkaline $\mathrm{pH}$, manipulation of urine $\mathrm{pH}$ may possibly cause an increase in the renal clearance of a drug with these characteristics. 4,23,38

Urine alkalinization increases, for instance, the clearance of salicylates, phenobarbital, chlorpropamide and methotrexate, 38 and should be considered for the treatment of moderate salicylate poisoning when there is no need for hemodialysis. ${ }^{23,38}$ In phenobarbital poisoning, treatment with multiple-dose activated charcoal is superior to urine alkalinization. ${ }^{38}$ Although urine alkalinization may increase the clearance of chlorpropamide, and may be useful in treating these poisonings, it is essential to have a strict control over blood glucose levels. ${ }^{38}$ Hypokalemia is the most common complication of urine alkalinization, which may be overcome with intravenous administration of potassium. There might be tetany due to alkalemia; hypocalcemia is rare. ${ }^{38}$

\section{Dialysis, hemoperfusion and hemofiltration}

Invasive procedures, such as hemodialysis, hemoperfusion, and hemofiltration, which increase the extracorporeal elimination of drugs are occasionally used in some severe cases of poisoning (see Table 4), but their efficiency is arguable. In general, extracorporeal elimination is considered efficient when it increases total body clearance by $30 \%$ or more. 4,9

Table 4 - Frequency of major treatments used to treat toxic exposure. Data from AAPCC-TESS (USA, 2003)

\begin{tabular}{|c|c|}
\hline $\begin{array}{l}\text { Treatment used in } 2,395,582 \\
\text { toxic exposures }\end{array}$ & $\mathbf{n}$ \\
\hline \multicolumn{2}{|l|}{ Gastric decontamination } \\
\hline - Single-dose activated charcoal & 134,619 \\
\hline - Cathartics & 48,839 \\
\hline - Gastric lavage & 20,327 \\
\hline - Ipecac syrup & 9,284 \\
\hline - Bowel irrigation & 2,798 \\
\hline \multicolumn{2}{|l|}{ Measures to increase poison elimination } \\
\hline - Alkalinization & 7,875 \\
\hline - Multiple-dose activated charcoal & 5,793 \\
\hline - Hemodialysis & 1,509 \\
\hline - Hemoperfusion & 27 \\
\hline \multicolumn{2}{|l|}{ Antidotes and antagonists } \\
\hline - N-acetylcysteine (oral) & 14,710 \\
\hline - Naloxone & 11,452 \\
\hline - Flumazenil & 2,074 \\
\hline - $\mathrm{N}$-acetylcysteine (endovenous) & 1,886 \\
\hline - Atropine & 926 \\
\hline - Fomepizole & 830 \\
\hline - Glucagon & 640 \\
\hline - Phytonadione (K vitamin) & 559 \\
\hline - Antidigoxin Fab fragments & 446 \\
\hline - Ethanol & 426 \\
\hline - Hyperbaric oxygen & 385 \\
\hline - Piridoxine & 341 \\
\hline - Methylene blue & 130 \\
\hline - Octreotide & 130 \\
\hline - Pralidoxime & 117 \\
\hline
\end{tabular}

AAPCC-TESS $=$ American Association of Poison Control Centers Toxic Exposure Surveillance System.

In order for dialytic procedures to be efficient, the toxic agent should have a low molecular weight, be highly soluble in water, have a low volume of distribution $(<2 \mathrm{~L} / \mathrm{kg})$ and low protein binding. Dialysis may be useful in severe poisonings caused by salicylates; methanol and ethylene glycol, when fomepizole is not available; 
vancomycin and lithium.4,9,39 Hemoperfusion and hemofiltration are seldom used, due to their high cost. Hemoperfusion is hypothetically better indicated in situations in which the toxic agent is poorly soluble in water and has a high affinity for the adsorbents used, whereas hemofiltration can remove toxic agents with a high molecular weight. ${ }^{4,9}$

\section{Antidotes}

Few antidotes and antagonists indicated for poisoning management are available, safe and efficacious. ${ }^{1,4,9}$ The consumption of and experience with the use of these drugs varies considerably from region to region. In the United Kingdom and in the USA the use of $\mathrm{N}$-acetylcysteine is quite frequent due to the large number of acetaminophen poisonings. ${ }^{1,4,9}$ The same applies to naloxone in the USA, due to the use of illicit drugs such as "heroin" and to the treatment of toxic exposure to clonidine.1,4,9, In Brazil, given the high frequency of exposure to organophosphorate and carbamate pesticides, including aldicarb, the use of atropine is extremely frequent. Table 5 shows the major antidotes/antagonists and their indications of use, whereas Table 4 shows the frequency of their use in the USA in 2003, according to AAPCC-TESS data. Except for atropine and oximes, the major new antidotes are described next.

\section{Naloxone}

Opioids are primarily prescribed for the treatment of pain and cough. They are classified into natural (morphine, codeine), semisynthetic (heroin, hydromorphine, oxymorphine) and synthetic (meperidine, methadone, paregoric, diphenoxylate, fentanyl, propoxyphene). ${ }^{40}$ All three opioid types are antagonist to their specific receptors. Poisoning is characterized by signs of low level of alertness, miosis and hypoventilation. 40 Hypothermia and bradycardia may be present in very young children. 40 Toxicologic urine tests yield false-positive and falsenegative results and are only qualitative. ${ }^{40} \mathrm{Naloxone}$ is an opioid receptor antagonist, and has been used as a diagnostic and therapeutic tool in opioid-induced coma. 40 It has a rapid action and may be crucial in the differential diagnosis of coma, avoiding the request for unnecessary exams such as lumbar puncture, cranial computed tomography, or even invasive procedures, such as endotracheal intubation. ${ }^{40}$ The AAP recommends an initial intravenous dose of $0.1 \mathrm{mg} / \mathrm{kg}$ in children up to five years of age. ${ }^{41}$ In older children, a minimum dose of $2 \mathrm{mg}$ is recommended, and can be repeated after three minutes, up to a maximum of $10 \mathrm{mg} .{ }^{40-41}$ If no response is obtained after this dose, the diagnosis of opioid poisoning must be reconsidered. $40-41$

Table 5 - Major antidotes/antagonists and their indications of use

\begin{tabular}{|c|c|}
\hline Toxic agent & Antidotes/antagonists \\
\hline Acetaminophen & $\mathrm{N}$-acetylcysteine \\
\hline Opioids & Naloxone \\
\hline Benzodiazepines & Flumazenil \\
\hline Acetylcholinesterase inhibitors (organofosforados e carbamatos) & Atropine \\
\hline Organophosphorates & Oximes (pralidoxime, obidoxime*) \\
\hline Methemoglobinizing substances & Methylene blue \\
\hline Iron salts & Deferoxamine \\
\hline Isoniazid & Piridoxine \\
\hline Digoxin & Antidigoxin ac (Fab)* \\
\hline Oral hypoglycemiant susbstances (sulphonylureas) & Octreotide \\
\hline Beta-blockers & Glucagon \\
\hline Metoclopramide, haloperidol (acute dystonia) & Diphenhydramine, biperiden \\
\hline Carbon monoxide & $\mathrm{O} 2$ to $100 \%, 1-3 \mathrm{~atm}$ \\
\hline Thyroxine & Propranolol \\
\hline Methanol/ethylene glycol & Ethanol/fomepizole* \\
\hline Warfarin, dicumarinic & $\mathrm{K}$ vitamin (phytonadione) \\
\hline Tricyclic antidepressants & Sodium bicarbonate \\
\hline Lead & DMSA*/EDTA/BAL \\
\hline Arsenic & BAL/Penicillamine \\
\hline Mercurium & BAL/Penicillamine/DMSA* \\
\hline Cyanide & $\begin{array}{c}\text { Amyl nitrite* + Sodium nitrite + sodium thiosulphate/ } \\
\text { Kelocyanor*/Hydroxocobalamin* }\end{array}$ \\
\hline
\end{tabular}

* Not available in Brazil. 
Clonidine is an $\alpha_{2}$-agonist derived from imidazoline, used as central antihypertensive. ${ }^{42}$ As it is opioid-like, clonidine has been indicated for the treatment of patients with opioid dependency. ${ }^{42-43}$ AAPCC-TESS data (19931999) show a significant increase in clonidine exposure in children, related to an increase in the prescription of this drug for the management of attention deficit hyperactivity disorder. 42 Clonidine poisoning causes clinical manifestations that resemble those of topical decongestants containing imidazoline derivatives, ${ }^{44}$ with rapid onset of action, 30 to 60 minutes after exposure. 9,42 Common clinical signs in children include central nervous system depression, hypothermia, bradycardia, miosis, and respiratory depression, which develop when a dose of clonidine greater than $10 \mu \mathrm{g} / \mathrm{kg}$ is ingested. ${ }^{9}$ Treatment is based on supportive care. ${ }^{9,42,44}$ Naloxone has been empirically used and no controlled studies exist that support its use. ${ }^{9,42-43}$

\section{Flumazenil}

Benzodiazepines are among the most widely prescribed drugs around the world and are the major cause of toxic exposure to medications in our setting. $40,45-47$ However, benzodiazepine poisoning has an exceptional lethal outcome.40,45-47 Benzodiazepines act upon the central nervous system by binding to benzodiazepine receptors in the GABA receptor chloride channel complex.40,45-47 The major signs of benzodiazepine poisoning are central nervous system depression, impaired $\mathrm{CO}_{2}$ ventilatory response, and decreased respiratory frequency. ${ }^{40,45-47}$ Toxicological urine tests often yield false-negative results, are time-consuming and expensive. ${ }^{40,45-47}$ Flumazenil is an antagonist to benzodiazepine receptors. In clinical controlled trials, it has proved efficient and relatively safe in patients with CNS depression caused by exclusive benzodiazepine poisoning. 40,45-47 The most important side effects include agitation, nausea, vomiting, irritability, and resedation. The adverse effects of the drug have made some authors contest its empirical use in comatose patients. ${ }^{46-47}$ Seizures, including convulsive status epilepticus and cardiac arrhythmia after the use of flumazenil, have been reported, most of them in patients who had been using proconvulsant drugs such as tricyclic antidepressants. Therefore, it is essential to have the patient's detailed clinical history before drug administration. ${ }^{46-47}$ Flumazenil is formally contraindicated in patients on chronic use of benzodiazepines who have a history of seizures (including febrile seizures) or myoclonus and in those with suspected or confirmed intake of other drugs that may lower the seizure threshold (tricyclic antidepressants, lithium, cocaine, methylxanthines, isoniazid, propoxyphene, monoamine oxidase inhibitors). ${ }^{46-}$ 47 Electrocardiogram evaluation has been recommended before the administration of flumazenil, in order to detect possible abnormalities commonly observed in tricyclic antidepressant poisoning, such as sinus tachycardia and prolongation of the QRS interval. ${ }^{46-47}$ The initial dose of flumazenil should be $0.02 \mathrm{mg} / \mathrm{kg}$ (maximum of $0.2 \mathrm{mg} /$ dose), and may be repeated every minute, with subsequent doses of $0.02 \mathrm{mg} / \mathrm{kg}$ (maximum of $0.3-0.5 \mathrm{mg} /$ dose) up to the total maximum dose of $3 \mathrm{mg}$. The drug has a shortacting effect, which ranges from 20 to 40 minutes. $40,45-47$

\section{$N$-acetylcysteine}

$\mathrm{N}$-acetylcysteine is the antidote used in cases of acetaminophen (paracetamol) poisoning. Acetaminophen is basically metabolized by the liver alone, with over $90 \%$ being converted to nontoxic glucoronidated and sulfated conjugates. ${ }^{9,48-51}$ Less than $5 \%$ is excreted unchanged in the urine and $5 \%$ is metabolized by several cytochrome P450 enzymes, converted to a highly reactive toxic metabolite, $\quad \mathrm{N}$-acetyl-p-benzoquinoneimine (NAPQI).9,48-51 In toxic doses ( $>200 \mathrm{mg} / \mathrm{kg}$ for children), $49-50$ excessive NAPQI is formed, depleting the hepatic stores of glutathione. ${ }^{9,49-51}$ Admittedly, NAPQI causes liver injury when hepatic glutathione stores fall below $30 \%$ of normal levels. ${ }^{49}$ Clinical findings of hepatotoxicity develop within 24 to 48 hours of ingestion, with right hypochondrial pain, weakness, jaundice and a rise in the levels of AST, ALT and bilirubins. Peak hepatotoxicity occurs after 72 to 96 of ingestion, and may cause liver and renal failure, which sometimes requires emergency liver transplantation. In those patients who recover from the poisoning, liver function returns to normal within four weeks. ${ }^{49}$ Children show less hepatotoxicity than adults, maybe due to the larger amount of glutathione in their liver. ${ }^{50-51} \mathrm{~N}$-acetylcysteine increases glutathione synthesis, may replace glutathione in NAPQI detoxification and may provide a substrate for acetaminophen sulfate formation, increasing the production of nontoxic metabolites. ${ }^{49}$ The use of this antidote should be considered in case of toxic doses, together with the interpretation of serum acetaminophen levels, measured between 4 and 24 hours of ingestion, using the Rumack-Matthew nomogram. ${ }^{9-49}$ The recommended (loading) dose is $140 \mathrm{mg} / \mathrm{kg}$, followed by $70 \mathrm{mg} / \mathrm{kg}$ every four hours, in a total of 18 doses, diluted at $5 \%$ and given orally. ${ }^{9-49}$ Although the cases of severe exposure to acetaminophen are rare in Brazil, they are expected to rise, given the increase in the consumption of this drug after a nation-wide dengue fever epidemic.

\section{Methylene blue}

Usually, the treatment recommended for patients with methemoglobin levels greater than $30-40 \%$ of hemoglobin consists of intravenous administration of methylene blue (concentration of $1-2 \%$, in the dose of $1-2 \mathrm{mg} / \mathrm{kg}$ ). 52 Methylene blue, via NADPH-methemoglobin reductase, is reduced to leukomethylene blue, which in its turn reduces methemoglobin to hemoglobin. Since the effect of methylene blue is relatively short and the half-life of dapsone is long, recurrence of methemoglobinemia is not uncommon in this type of exposure, and occasionally, supplemental doses of methylene blue are necessary. 52 However, doses of methylene blue greater than $7 \mathrm{mg} / \mathrm{kg}$ may exacerbate methemoglobinemia and hemolysis, due to its oxidative effect. A study of children with severe methemoglobinemia (levels greater than 20\%) due to 
dapsone exposure suggests that the administration of multiple-dose activated charcoal minimizes the need for repeated doses of methylene blue and their complications. 52

\section{Fomepizole}

Fomepizole is a competitive antagonist to lactic dehydrogenase, indicated for acute methanol or ethylene glycol poisoning, which causes high morbidity and mortality. ${ }^{3,9,23}$ The usual treatment of these poisonings consists of the administration of high doses of ethanol, in order to obtain a serum concentration close to $100 \mathrm{mg} / \mathrm{dl}$ (state of inebriation). ${ }^{3,9,23}$ Ethanol has a higher affinity for lactic dehydrogenase than methanol or ethylene glycol, preventing the production of highly toxic metabolites, formaldehyde, formic acid in case of methanol; glycoaldehyde, glycolic and oxalic acids, in case of ethylene glycol. $3,9,23$ Since this procedure extends the half-life of these alcohols, hemodialysis is indicated, but it is necessary to escalate the ethanol doses to maintain the levels of enzyme inhibition, as ethanol is also dialyzable (low $\mathrm{Vd}$, $<2 \mathrm{l} / \mathrm{kg}$ ). Although fomepizole therapy is expensive, management of these cases is simpler and less invasive, reducing the necessity of dialysis and associated complications, such as ethanol-induced hypoglycemia, and also reducing the length of treatment and hospital stay. The loading dose is $15 \mathrm{mg} / \mathrm{kg}$, followed by four doses of $10 \mathrm{mg} / \mathrm{kg}$ every 12 hours and then $15 \mathrm{mg} / \mathrm{kg}$ every 12 hours, always given intravenously, in a 30-minute infusion. It is indicated when the serum concentration of ethylene glycol or methanol exceeds $20 \mathrm{mg} / \mathrm{dl}^{3}, 9,23$

\section{Octreotide}

Sulfonylureas are commonly used in patients with non-insulin-dependent diabetes mellitus, and act by increasing the amount of intracellular ATP and the sensitivity of insulin receptor. ${ }^{3,9}$ The most widely prescribed sulfonylureas are glyburide, glipizide and chlorpropamide. Besides the classic symptoms of hypoglycemia, there may be severe complications, such as convulsive status epilepticus and cardiovascular collapse. Monitoring of blood glucose levels must be performed during 24 hours after ingestion, even in asymptomatic patients. ${ }^{3,9}$ Administration of octreotide should be considered when no response is obtained with the infusion of $1 \mathrm{~g} / \mathrm{kg}$ of glucose and with the intake of calorie-rich foods. ${ }^{3,9}$ Octreotide, a somatostatin analog, suppresses insulin release by binding to the somatostatin receptor, which blocks the calcium channel. When this channel is blocked, insulin release is reduced. Subcutaneous or intravenous administration is possible. ${ }^{3,9}$ The conventional dose is $50 \mu \mathrm{g}$ given subcutaneously every eight to 12 hours. The dose and the dosing interval vary according to the amount of sulfonylurea ingested. The antihypertensive agent diazoxide also inhibits insulin release, and may be used an efficient antidote to incidental sulfonylurea ingestion. However, the concern with hypotension restricts its use in pediatric patients. 3,9

\section{Final remarks}

Prevention is the major "treatment" for toxic exposures. Creating a safe environment where children can grow safely is of paramount importance. After analyzing the data shown in this study, it is imperative that a law obliging the use of child-resistant packaging be passed in Brazil. Sodium hydroxide can be easily bought in any supermarket, being packaged in plain plastic bags! Severe exposures to these products are quite common and, although these exposures pose a small risk of death, they have high morbidity and a high incidence of sequelae. Over-the-counter medications are sold without a prescription. These drugs include, for instance, topical decongestants containing naphazoline, whose use is arguable and unsafe in children under the age of six years, and which contain totally inappropriate concentrations for pediatric use.

Although most toxic exposures in children are accidental and of mild severity, iatrogenic procedures, especially gastrointestinal decontamination, are still used. It is crucial that medical schools and medical residency programs in Pediatrics emphasize this topic in their syllabuses. Pediatricians must educate their patients as well as their caretakers about basic preventive measures, helping them to eliminate the use of emetics in the household and telling them about the importance of calling the poison control center whenever they need information on a drug. Finally, health authorities must invest in poison control centers in Brazil, in order to ameliorate the quality of service, improve the qualification of health professionals and expand their service capacity. The cost-benefit ratio to the society as a whole has been certainly demonstrated.

\section{References}

1. Watson W, Litovitz TL, Klein-Schwartz W, Rodgers GC, Youniss J, Reid N, et al. 2003 Annual Report of the American Association of Poison Control Centers Toxic Exposure Surveillance System. Am J Emerg Med. 2004;22:335-404.

2. Liebelt $E L$, DeAngelis $C D$. Evolving trends and treatment advances in pediatric poisoning. JAMA. 1999;282:1113-15.

3. Tenenbein M. Recent advances in pediatric toxicology. Pediatr Clin North Am. 1999;46:1179-88.

4. Riordan M, Rylance G, Berry K. Poisoning in children 1: general management. Arch Dis Child. 2002;87:392-6.

5. Riordan M, Rylance G, Berry K. Poisoning in children 2: painkillers. Arch Dis Child. 2002;87:397-9.

6. Riordan M, Rylance G, Berry K. Poisoning in children 3: common medicines. Arch Dis Child. 2002;87:400-2.

7. Riordan M, Rylance G, Berry K. Poisoning in children 4: household products, plants, and mushrooms. Arch Dis Child. 2002;87:403-6.

8. Riordan M, Rylance G, Berry K. Poisoning in children 5: rare and dangerous poisons. Arch Dis Child. 2002;87:407-10.

9. Abbruzzi G, Stork CM. Pediatric toxicologic concerns. Emerg Med Clin North Am. 2002;20:223-47.

10. Sistema Nacional de Informações Tóxico-Farmacológicas SINITOX. Casos Registrados de Intoxicação Humana e Envenenamento. Brasil, 2002. www.fiocruz.br/sinitox/2002/ brasil2002.htm. Acesso: 14/09/2005.

11. Rodgers GB. The safety effects of child-resistant packaging for oral prescription of drugs. Two decades of experience. JAMA. 1996;275:1661-5.

12. American Academy of Pediatrics, Committee on Injury, Violence, and Poison Prevention. Poison treatment in the home. Pediatrics. 2003;112:1182-5. 
13. Krenzelok EP, McGuigan $M$, Lheureux $P$. AACT/EAPCCT position statement: ipecac syrup. J Toxicol Clin Toxicol. 1997;35:699-709.

14. Vale GA. AACT/EAPCCT position statement: gastric lavage. J Toxicol Clin Toxicol. 1997;35:711-19.

15. Chyka PA, Seger D. AACT/EAPCCT position statement: singledose activated charcoal. J Toxicol Clin Toxicol. 1997;35:721-41.

16. Barceloux D, McGuigan M, Hartigan-Go K. AACT/EAPCCT position statement: cathartics. J Toxicol Clin Toxicol. 1997;35:743-52.

17. Tenenbein M. AACT/EAPCCT position statement: whole bowel irrigation. J Toxicol Clin Toxicol. 1997;35:743-52.

18. Manoguerra AS, Krenzelok EP, McGuigan M, Lheureux P. AACT/ EAPCCT position paper: ipecac syrup. J Toxicol Clin Toxicol. 2004;42:133-43.

19. Lheureux $P$, Tenenbein M. AACT/EAPCCT position paper: whole bowel irrigation. J Toxicol Clin Toxicol. 2004;42:843-54.

20. Kulig K, Vale JA. AACT/EAPCCT position paper: gastric lavage. J Toxicol Clin Toxicol. 2004;42:933-43.

21. Krenzelok EP, Vale JA, Chyka PA, Seger D. AACT/EAPCCT position paper: single-dose activated charcoal. J Toxicol Clin Toxicol. 2005;43:61-87.

22. Bond GR. Home syrup of ipecac use does not reduce emergency department use or improve outcome. Pediatrics. 2003;112: 1061-4.

23. Krenzelok EP. New developments in the therapy of intoxications. Toxicol Letters. 2002;127:299-305.

24. Manoguerra AS, Cobaugh DJ. Guideline on the use of ipecac syrup in the out-of-hospital management of ingested poisons. Clin Toxicol. 2005;43:1-10.

25. Krenzelok EP. Ipecac syrup-induced emesis. No evidence of benefit. Clin Toxicol. 2005;43:11-12.

26. Seger D. Parallax view. Clin Toxicol. 2005;43:13-15.

27. Eddleston M, Juszczac E, Buckley N. Does gastric lavage really push poisons beyond the pylorus? A systematic review of the evidence. Ann Emerg Med. 2003;42:359-64.

28. Seger D. Single-dose activated charcoal-backup and reassess. J Toxicol Clin Toxicol. 2004;42:101-10.

29. Sitar GR, Tenenbein M. Effect of anticholinergic drugs on the efficacy of activated charcoal. J Toxicol Clin Toxicol. 2004;42: 267-72.

30. Spiller HA, Rodgers Jr GC. Evaluation of administration of activated charcoal in the home. 2001; 108 (6):E100. www.pediatrics.org/cgi/content/full/108/6/e100.

31. Scharman EJ, Cloonan HA, Durback-Morris LF. Home administration of charcoal: can mothers administer a therapeutic dose? J Emerg Med. 2001;21:357-61.

32. Bond GR. Activated charcoal in the home: helpful and important or simply a distraction? Pediatrics. 2002;109:145-6.

33. James LP, Nichols MH, King WD. A comparison of cathartics in pediatric ingestions. Pediatrics. 1995;96:235-8.

34. AACT/EAPCCT position statement and practical guidelines on the use of multiple dose-activated charcoal in the treatment of acute poisoning. J Toxicol Clin Toxicol. 1999;37:731-51.

35. Tenenbein M. Multiple-dose activated charcoal: time for reappraisal II. Ann Emerg Med. 2003;42:597-8.

36. Dorrington $\mathrm{CL}$, Johnson DW, Brant $\mathrm{R}$, et al. The frequency of complications associated with the use of multiple-dose activated charcoal. Ann Emerg Med. 2003;41:370-7.

37. Eroglu A, Kucuktulu U, Ercyes N, Turgutalp H. Multiple doseactivated charcoal as a cause of acute appendicitis. J Toxicol Clin Toxicol. 2003;41:71-3.
38. Proudfoot AT, Vale JA, Krenzelok EP. Position paper on urine alkalinization. J Toxicol Clin Toxicol. 2004;42:1-26.

39. Higgins RM, Connolly JO, Hendry BM. Alkalinization and hemodialysis in severe salicylate poisoning: comparison of elimination techniques in the same patient. Clin Nephrol. 1998;50:178-83.

40. Perry HE, Shannon MW. Diagnosis and management of opioid and benzodiazepine - induced comatose overdose in children. Curr Opin Pediatr. 1996;8:243-7.

41. American Academy of Pediatrics Committee on Drugs. Naloxone dosage and route of administration for infants and children: addendum to emergency drug doses for infants and children. Pediatrics. 1990;86:483-4.

42. Klein-Schwartz W. Trends and toxic effects from pediatric clonidine exposures. Arch Pediatr Adolesc Med. 2002;156:392-5.

43. Liebelt EL. The use of naloxone for resuscitation of non-opioid toxicity. Abstracts of the XXIII Congress of the European Association of Poison Centres and Clinical Toxicologists (EAPCCT); 2003 May 20-23; Roma- Italy: abstract n. 30.

44. Bucaretchi F, Dragosavac S, Vieira JR. Exposição aguda a derivados imidazolínicos em crianças. J Pediatr (Rio J). 2003;79:519-24.

45. The flumazenil in benzodiazepine intoxication Multicenter Study Group: treatment of benzodiazepine overdose with flumazenil. Clin Ther. 1992;14:978-95.

46. Geller E, Crome P, Challer MD, Marchant B. Risks and benefits of therapy with flumazenil (Lanexate) in mixed drug intoxications. Eur Neurol. 1991;31:241-50.

47. Seger DL. Flumazenil - treatment or toxin. J Toxicol Clin Toxicol. 2004;42:209-16.

48. Harrison PM, Keays R, Bray GP. Improved outcome of acetaminophen-induced fulminant hepatic failure by late administration of acetylcystine. Lancet. 1990;335:1572-3.

49. Marzullo L. An update of $\mathrm{N}$-acetylcisteine treatment for acute acetaminophen toxicity in children. Curr Opin Pediatr. 2005; 17:239-45.

50. Tenebein M. Acetaminophen: the $150 \mathrm{mg} / \mathrm{kg}$ myth. J Toxicol Clin Toxicol. 2004;42:145-8.

51. Bond RG. Reduced toxicity of acetaminophen in children: it's the liver. J Toxicol Clin Toxicol. 2004;42:149-52.

52. Bucaretchi F, Miglioli L, Baracat EC, Madureira PR, De Capitani EM, Vieira JR. Exposição aguda à dapsona e metemoglobinemia em crianças: tratamento com doses múltiplas de carvão ativado. J Pediatr (Rio J). 2000;76:290-4.

Correspondence:

Fábio Bucaretchi

Depto. de Pediatria e Centro de Controle de Intoxicações, FCM, HCUNICAMP

CX. P. 6111 CEP 13083-970 - Campinas, SP, Brazil

Tel.: + 55 (19) 3788.8875

Fax: + 55 (19) 3788.8873

E-mail: bucaret@fcm.unicamp.br 